\title{
Changes in cloudiness over the Amazon rainforests during the last two decades: diagnostic and potential causes
}

\author{
Paola A. Arias • Rong Fu • Carlos D. Hoyos • \\ Wenhong Li $\cdot$ Liming Zhou
}

Received: 17 February 2010/Accepted: 24 August 2010/Published online: 4 September 2010

(C) The Author(s) 2010. This article is published with open access at Springerlink.com

\begin{abstract}
This study shows a decrease of seasonal mean convection, cloudiness and an increase of surface shortwave down-welling radiation during 1984-2007 over the Amazon rainforests based on the analysis of satelliteretrieved clouds and surface radiative flux data. These changes are consistent with an increase in surface temperature, increased atmospheric stability, and reduction of moisture transport to the Amazon based on in situ surface and upper air meteorological data and reanalysis data. These changes appear to link to the expansion of the western Pacific warm pool during the December-February season, to the positive phase of the Atlantic Multidecadal
\end{abstract}

P. A. Arias - R. Fu

Department of Geological Sciences,

The University of Texas at Austin, Austin, TX, USA

P. A. Arias

Grupo de Ingeniería y Gestión Ambiental (GIGA),

Universidad de Antioquia, Medellín, Colombia

C. D. Hoyos · L. Zhou

School of Earth and Atmospheric Sciences,

Georgia Institute of Technology, Atlanta, GA, USA

W. Li

Division of Earth and Oceanic Sciences,

Nicholas School of the Environment,

Duke University, Durham, NC, USA

L. Zhou

Climate and Large Scale Dynamics Program,

National Science Foundation, Arlington, VA, USA

P. A. Arias $(\bowtie)$

Geology Foundation, Jackson School of Geosciences,

PO Box B, Austin, TX 78713-8902, USA

e-mail: paola.arias@mail.utexas.edu
Oscillation and increase of SST over the eastern Pacific SST during the March-May season, and to an increase of the tropical Atlantic meridional SST gradient and an expansion of the western Pacific warm pool during September-November season. The resultant increase of surface solar radiation during all but the dry season in the Amazon could contribute to the observed increases in rainforest growth during recent decades.

Keywords Amazon forests - Cloudiness - Climate variability · Amazon growth rate $\cdot$ AMO $\cdot$ Atlantic SST gradient

\section{Introduction}

Tropical forests contain as much as $40 \%$ of the carbon stored as terrestrial biomass and account for 30-50\% of terrestrial productivity (Phillips et al. 1998). Approximately $55 \%$ of the contingent rainforest is located in the Amazon basin. This river basin also provides $\sim 18 \%$ of global fresh water discharge. Through its control on evapotranspiration and runoff, the Amazon rainforest plays an important role in regulating the water cycle in this basin. The Amazon hosts the wettest tropical rainforest with a mean annual rainfall of 1,500-3,000 mm. These forests exhibit flushes of new leaf growth with increased photosynthesis in the dry season that closely coincide with seasonal peaks in solar irradiance (Myneni et al. 2007; Wright and van Schaik 1994), indicating that photosynthesis in these rainforests is radiation limited (Shuttleworth 1989), instead of water limited. The balance of the Amazon forest is primarily determined by land use and climate change and has important consequences to the global carbon and water cycle. 
Recent studies have reported a wide spread increase in the growth and mortality rates of mature rainforest (Phillips et al. 1998; Nemani et al. 2003; Lewis et al. 2004a). Such an increase in growth rate is more robust over the forests that are least disturbed by human activities (e.g. western Amazon) suggesting that a direct impact of land use is unlikely to be the cause. Several causes have been hypothesized including $\mathrm{CO}_{2}$ fertilization, climate change, increase in aerosol induced diffused light, and nutrient recycling (Laurance et al. 2004; Nemani et al. 2003; Gu et al. 2003; Artaxo et al. 2002; Lewis et al. 2004b). Among them, $\mathrm{CO}_{2}$ fertilization has received the most attention (Lewis et al. 2004a, b; Laurance et al. 2004). However, Nemani et al. (2003) and Ichii et al. (2005) suggest that the rate of increase in forest growth is too large to be explained by $\mathrm{CO}_{2}$ fertilization alone and proposed changes in solar radiation, most likely due to changes in cloudiness, as a possible contributor. However, whether cloudiness has changed significantly over tropical forests, and if so, what is the cause of such a change is not clear.

Decadal change of cloudiness over the global tropics has been detected (Wielicki et al. 2002; Chen et al. 2002). Over South America, Warren et al. (2007) found a declining trend in cloudiness analyzing an in situ product. Other studies indirectly associated with cloudiness suggest mixed conclusions. Analysis of long-term rain gauges in the Amazon basin suggest that decadal change of rainfall is insignificant over the southern Amazon $\left(5-15^{\circ} \mathrm{S}\right)$ and marginally significant in the northern Amazon $\left(5^{\circ} \mathrm{S}-5^{\circ} \mathrm{N}\right.$; Marengo 2004). Decadal change in runoff is significant, but such changes have been attributed either to changes in evapotranspiration (Gedney et al. 2006) or to land use (Coe et al. 2009). The association of these previous studies to decadal changes of cloudiness is not clear.

What processes could potentially cause decadal variability of the cloudiness over the Amazon? Many previous studies have explored the empirical links between rainfall changes in South America and several well-known sources of decadal variability in the tropics. For example, Marengo (2004) identified a correlation between wetter conditions over the entire forest during 1946-1975 associated with the cold phase of the Pacific Decadal Oscillation (PDO; Mantua et al. 1997) and drier conditions over the western Amazon during 1976-1998 associated with the warm phase of the PDO. Kayano and Andreoli (2007) found that El Niño-Southern Oscillation (ENSO) effects in rainfall over South America are enhanced (weakened) when ENSO and PDO are in the same (opposite) phases. Using a set of model simulations, Knight et al. (2006) show that the positive Atlantic Multidecadal Oscillation (AMO; Kerr 2000) phase is associated with a northward displacement of precipitation over the tropical Atlantic Ocean, along with a northward cross-equatorial wind anomaly. These changes imply a shift in the mean Intertropical Convergence Zone (ITCZ) to the north of its climatological March-April-May (MAM) position, and hence a reduction in northeastern Brazil rainfall.

A positive phase of the Indian Ocean Dipole (IOD; Saji et al. 1999) is also found to be correlated with an anomalous divergence and thus negative rainfall anomaly over central Brazil (Chan et al. 2008). Saji and Yamagata (2003) show that positive IOD events are associated with warm land surface anomalies and reduced rainfall over Brazil. How these changes of decadal modes over the tropical oceans influence cloudiness over Amazon has not been investigated thoroughly.

In addition to tropical influences, rainfall over the Amazon is also modulated by extratropical variability. Wave trains extending along the south Pacific link convective pulses to the South Pacific Convergence Zone (SPCZ) and South Atlantic Convergence Zone (SACZ) regions (Kalnay et al. 1986; Grimm and Silva Dias 1995; Nogues-Paegle and Mo 1997; Lenters and Cook 1995). Positive rainfall anomalies in the SACZ region are, in turn, associated with negative rainfall anomalies in the Amazon on both intraseasonal and interannual scales (e.g., NoguesPaegle and Mo 1997; Liebmann et al. 2004). Fu et al. (2001) report that a wave train anomaly in the south Pacific and American sector could produce upper level cyclonic conditions that in turn potentially suppress precipitation over the eastern Amazon.

Although rainfall variability over the Amazon basin has been investigated in the past, changes in cloudiness over these forests have not been studied in detail. In this study, we examine whether cloudiness and surface solar radiation have changed over this region from 1984 to 2007, and if so, how these changes are linked to tropical decadal climate variability. To answer this question, we will show the trends in cloudiness and solar incoming radiation over the Amazon basin, the links between the changes of cloudiness and decadal variability over the adjacent oceans, and discuss the underlying mechanisms that have contributed to the observed links. This paper is organized as follows. Data and methodology are described in Sect. 2. Results are presented in Sect. 3. The implications of these results to Amazon rainforest growth are discussed in Sect. 4. Finally, conclusions are given in Sect. 5.

\section{Data and methodology}

The International Satellite Cloud Climatology Project (ISCCP) cloudiness and solar incoming radiation, and the National Oceanic and Atmospheric Administration (NOAA) interpolated Outgoing Longwave Radiation (OLR) datasets are analyzed to determine the changes of 
cloudiness and resultant change in downward surface solar radiation over the Amazon during the period 1984-2007. Other variables, such as surface temperature, relative and specific humidity, vertically integrated moisture transport (VIMT), sea surface temperature anomalies (SSTA) as well as other well-established indices of sea surface temperature (SST) variability are also studied in order to uncover the physical processes associated with regional changes in cloudiness over the Amazon basin. Trends of these variables are estimated using the non-parametric Mann-Kendall test (Sen 1968). Correlation and composite analyses are used to link cloud cover variability in South America with tropical climate variability. Due to differences in rainfall seasonality between the northern and southern Amazon regions (Wang and $\mathrm{Fu}$ 2002; Marengo 2005), the Amazon basin is divided in two parts: the northern Amazon $\left(70^{\circ} \mathrm{W}-50^{\circ} \mathrm{W}, 5^{\circ} \mathrm{N}-5^{\circ} \mathrm{S}\right)$, and the southern Amazon $\left(70^{\circ} \mathrm{W}-50^{\circ} \mathrm{W}, 5^{\circ} \mathrm{S}-15^{\circ} \mathrm{S}\right)$ (Fig. 1$)$.

Monthly data from the ISCCP database for shortwave (SW) down-welling radiation (FD datasets) and clouds (D2 datasets) for a $2.5^{\circ}$ resolution during the period 1984-2007 (Rossow et al. 1996; Rossow and Schiffer 1999; Zhang et al. 2004), available at ISCCP website (http://isccp.giss. nasa.gov/index.html), are used. ISCCP-FD is a product of the Goddard Institute for Space Study (GISS) radiative transfer model calculation using inputs from the ISCCP cloud product (D1), the Television Infrared Observation Satellite (TIROS) Operational Vertical Sounder (TOVS) data, the Total Ozone Mapping Spectrometer data, along with other ancillary data for specifying the radiative properties of the atmospheric and surface (Zhang et al. 1995; Zhang et al. 2004). Thus, changes of surface
Fig. 1 Seasonal trend in $\mathbf{a}-$ d SW down-welling radiation and $\mathbf{e}-\mathbf{h}$ high cloudiness from ISCCP during 1984-2007 over the Tropical Americas. Trends shown are statistically significant at the $5 \%$ level according to the Mann-Kendall test with Sen's statistic (Sen 1968). Boxes represent northern and southern Amazon domains, respectively (a)

DJF

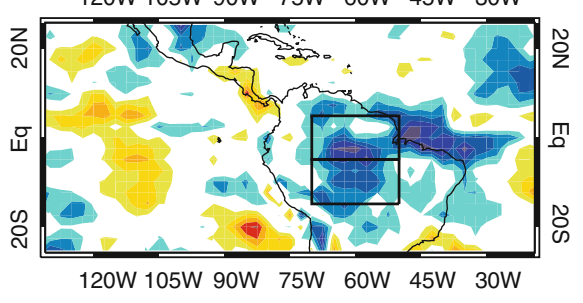

(b)

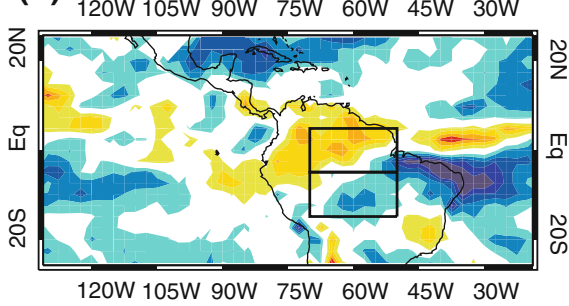

(c)

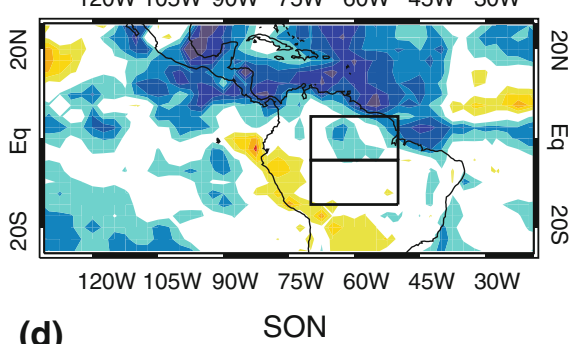

(d) 120W 105W 90W 75W 60W 45W 30W

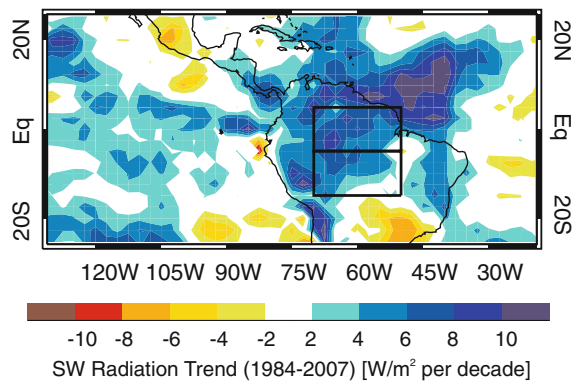

(e) DJF 120W 105W 90W 75W 60W 45W 30W

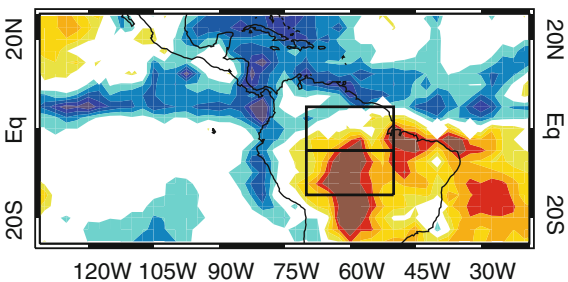

(f) $120 \mathrm{~W}$ 105W 90W $75 \mathrm{~W}$ 60W 45W 30W

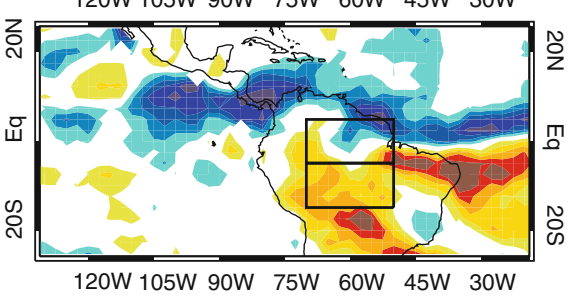

(g) $120 \mathrm{~W} 105 \mathrm{~W}$ 90W $75 \mathrm{~W}$ 60W 45W 30W

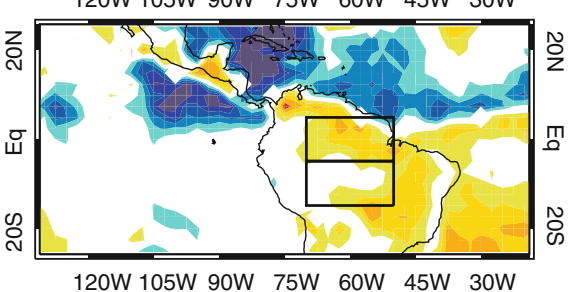

(h) SON

120W 105W 90W 75W 60W 45W 30W

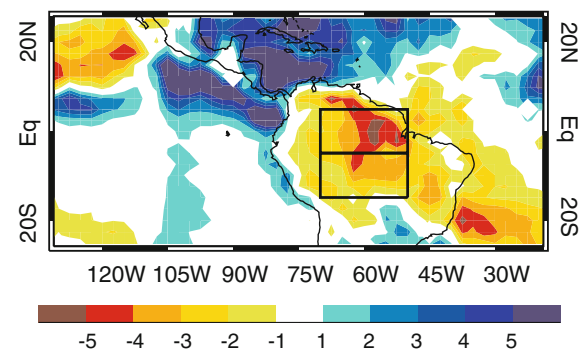

High Cloud Cover Trend (1984-2007) [\% per decade] 
downward solar radiation are mainly a result of change in cloudiness in the ISCCP data.

Recent studies have highlighted the sensitivity of ISCCP cloudiness to changes in satellite viewing angle caused by repositioning of the satellites (Campbell 2004; Norris 2005; Evan et al. 2007). Norris (2005) found that an increase in the number of geostationary satellites over time has produced a tendency towards lower viewing angles at many locations, thus generating an apparent decline in ISCCP planetary albedo and cloud cover. However, not all the types of clouds are equally affected by changes in satellite viewing angle. Low cloud top temperature is closer to the background clear sky temperature and thus is more sensitive to small changes in temperature due to shift of satellite viewing angle than middle and high-level clouds.

OLR data are obtained from polar-orbiting satellites. Its biases due to orbital drift or changes in satellite are uncorrelated to geostationary satellite repositions. Thus, monthly NOAA interpolated OLR on a $2.5^{\circ}$ resolution (Liebmann and Smith 1996) is used to verify the changes detected by ISCCP data.

Surface temperature, relative humidity, and specific humidity records correspond to in situ data interpolated in a $5^{\circ} \times 4^{\circ}$ grid for the period 1976-2005 are used. These records are provided and described by Dai (2006).

Monthly streamfunction at 0.22 sigma level $(\sim 200 \mathrm{hPa})$ and the VIMT calculated using the NCEP-NCAR Reanalysis (Kalnay et al. 1996) is also used. For calculations of VIMT, daily $2.5^{\circ}$ grid data for zonal and meridional wind and specific humidity at different pressure levels from the National Center for Environmental Project-National Center for Atmospheric Research (NCEP-NCAR) Reanalysis (Kalnay et al. 1996) are used. Since atmospheric moisture is an order of magnitude lower above the mid troposphere compared to that in the lower troposphere, the vertical integration is done between $1,000 \mathrm{hPa}$ and $600 \mathrm{hPa}$ levels over the northern Amazon and southern Amazon, respectively. VIMT is calculated by integrating the moisture flux over the box defined by the limits of the forest in consideration, as follows ( $\mathrm{Li}$ and $\mathrm{Fu} 2004)$

$$
\begin{aligned}
\text { VIMT }= & \frac{\left[\left(\overline{u q_{2}}-\overline{u q_{1}}\right)+\left(\overline{v q_{2}}-\overline{v q_{1}}\right)\right]}{\rho A} \\
\overline{u q_{\mathrm{i}}} & =\left[\frac{1}{g} \int_{\text {Lat1 }}^{\text {Lat2 }} \int_{p 2}^{p 1} u q \mathrm{~d} p \mathrm{~d} y\right]_{\text {Loni }} \\
\overline{v q_{\mathrm{i}}} & =\left[\frac{1}{g} \int_{\text {Lon1 }}^{\text {Lon2 }} \int_{p 2}^{p 1} v q \mathrm{~d} p \mathrm{~d} x\right]_{\text {Lati }}
\end{aligned}
$$

where $g$ is acceleration of gravity $\left(\mathrm{m} / \mathrm{s}^{2}\right), u$ is zonal wind $(\mathrm{m} / \mathrm{s}), v$ is meridional wind $(\mathrm{m} / \mathrm{s}), q$ is specific humidity $(\mathrm{kg} / \mathrm{kg}), p_{1}$ is pressure in the surface layer $(1,000 \mathrm{hPa}), p_{2}$ is pressure in the upper layer $(600 \mathrm{hPa})$, Lon 1 is longitude for the left side of the box, Lon2 is longitude for the right side, Lat1 is latitude for the southern side, Lat 2 is latitude for the northern side, $\rho$ is density of water $\left(1,000 \mathrm{~kg} / \mathrm{m}^{3}\right)$, and $A$ is the area of the box $\left(\mathrm{m}^{2}\right)$. Integrations are averaged on a monthly basis. Units for VIMT are given in $\mathrm{mm} /$ day and positive values represent convergence.

SST data is obtained from the extended reconstructed monthly mean SST from the NOAA Climate Diagnostic Center (CDC) (Reynolds 1988). The spatial resolution of the data is $2^{\circ} \times 2^{\circ}$. For the period of analysis considered here, the SST was derived from blended satellite and in situ measurements.

To identify how changes in cloudiness are linked to tropical climate variability, indices for PDO, expansion of the western Pacific warm pool, IOD, AMO, and tropical Atlantic SST gradient (SSTG) are considered. AMO index is available from http://www.cdc.noaa.gov/data/timeseries/ AMO/ (Enfield et al. 2001). PDO index is obtained from http://jisao.washington.edu/pdo/PDO.latest (Mantua et al. 1997). The intensity of the IOD is represented by the Dipole Mode Index (DMI) and is available at http://www. jamstec.go.jp/frsgc/research/d1/iod/dmi_nature.index. A warm pool area (WPA) index is defined as the area over the equatorial Pacific between $20^{\circ} \mathrm{S}-20^{\circ} \mathrm{N}$ and $140^{\circ} \mathrm{E}-150^{\circ} \mathrm{W}$, where SSTs are higher than $28^{\circ} \mathrm{C}$. This index is considered to be an overarching index of western Pacific variability. The tropical Atlantic SSTG is defined as the area mean SST difference between the north $\left(5^{\circ} \mathrm{N}-25^{\circ} \mathrm{N}, 60^{\circ} \mathrm{W}-\right.$ $\left.30^{\circ} \mathrm{W}\right)$ and south $\left(5^{\circ} \mathrm{S}-25^{\circ} \mathrm{S}, 30^{\circ} \mathrm{W}-0^{\circ} \mathrm{E}\right)$ Atlantic (Giannini et al. 2004). Niño 3, Niño 4, and Niño 3.4 indices are obtained from http://www.cdc.noaa.gov/data/climateindices/ List/.

Correlation coefficients are computed to identify the links between changes of cloudiness over the Amazon and those over the adjacent oceans. Trends are removed before computing correlations since the existence of a trend can induce spurious correlations that are not related to the interannual variability of cloudiness and SSTAs but only to the decreasing/increasing trends of the time series. The statistical significance of the correlations is determined by the Monte Carlo Test for spatial pattern (Livezey and Chen 1983). We perform 1,000 iterations and use a threshold percent for statistical significance equal to $95 \%(p=0.05)$.

Composites for positive ( $>1$ standard deviation, $\sigma$ ) and negative phases $(<-1 \sigma)$ of (i) PDO index, (ii) AMO index, (iii) western Pacific WPA, (iv) tropical Atlantic SSTG, and (v) Indian Ocean DMI is used. Given the limited occurrence of these events relative to total temporal samples, composite analysis would more clearly highlight of changes of cloudiness over the Amazon associated with the aforementioned indices than that provided by the 
correlation analysis. These composites are obtained with and without removal of the ENSO influence on these indices. The statistical significance of the difference between the composites for positive and negative phases is tested using a bootstrap test (Efron 1979). We perform 1,000 iterations with a threshold percentage for statistical significance equal to $95 \%(p=0.05)$, and use the bias corrected and accelerated percentile method for the confidence interval estimation.

In this study, correlation analysis is used to identify the SST anomalies patterns, thus the decadal SST variability modes that are linked to the changes of cloudiness over the Amazon. Composite cloud change associated with strong anomalies of these decadal modes is then analyzed.

\section{Results}

3.1 Changes in surface incoming radiation and convective cloudiness over the Amazon

Figure 1a-d show the seasonal trends in ISCCP SW downwelling radiation (contours) during 1984-2007 over the tropical Americas. Boxes show the geographical location for the northern and southern Amazon regions. Linear trends shown in these figures are statistically significant at the 5\% level according to the Mann-Kendall test (Sen 1968). The strongest trends have occurred in SeptemberOctober-November (SON) over the entire Amazon. A general increase in solar SW radiation over the southern
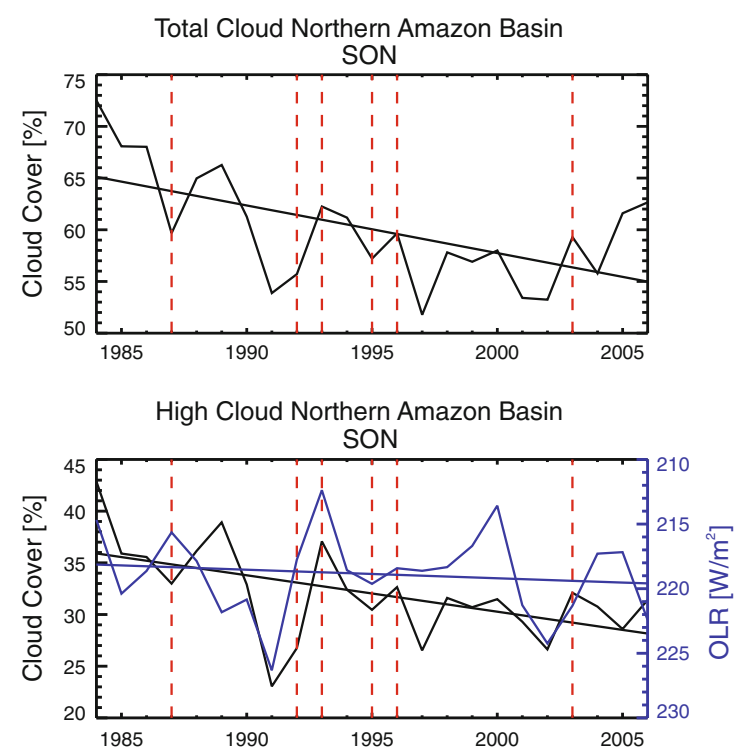

Fig. 2 Domain average time series for total and high clouds (black curves) and OLR (blue curves) during SON (DJF) over the northern (southern) Amazon. Domain average OLR is obtained for values lower than $240 \mathrm{~W} / \mathrm{m}^{2}$. Red dotted lines indicate the dates of satellite
Amazon domain also occurred during December-JanuaryFebruary (DJF) and MAM seasons. Decreasing total cloud cover over the Amazon is also observed (not shown), in agreement with Warren et al. (2007), who also found a declining trend in cloudiness analyzing an in situ product during the period 1971-1996 (see their Fig. 5).

The ISCCP data show a significant decrease in high clouds during the DJF and MAM seasons over the southern Amazon and during the SON season over the entire Amazon in Fig. 1e-h. Areas of decreasing high cloudiness over the Amazon generally coincide with increasing SW down-welling radiation, except over northwestern Amazon during the MAM season when the reduction of high clouds occurred mainly over the southern domain (Fig. 1). By contrast, low and middle clouds do not show any significant change (not shown). Figure 2 shows domain average time series for total and high clouds over the northern Amazon during SON and the southern Amazon during DJF, and the distribution of ISCCP satellite reposition dates during the period considered here. The changes of high clouds mostly occurred well within the field of view of the geostationary satellites, where change of satellite viewing angle has less impact on cloud detection than that near the edge of the satellite field of view. Thus, satellite changes do not appear to cause systematic decrease in total and high clouds over the region. By contrast, low-level clouds over oceans do show significant decrease (not shown) along the edge of the satellite field of view that matches the geostationary "footprints" due to satellite viewing angle change (Evan et al. 2007).
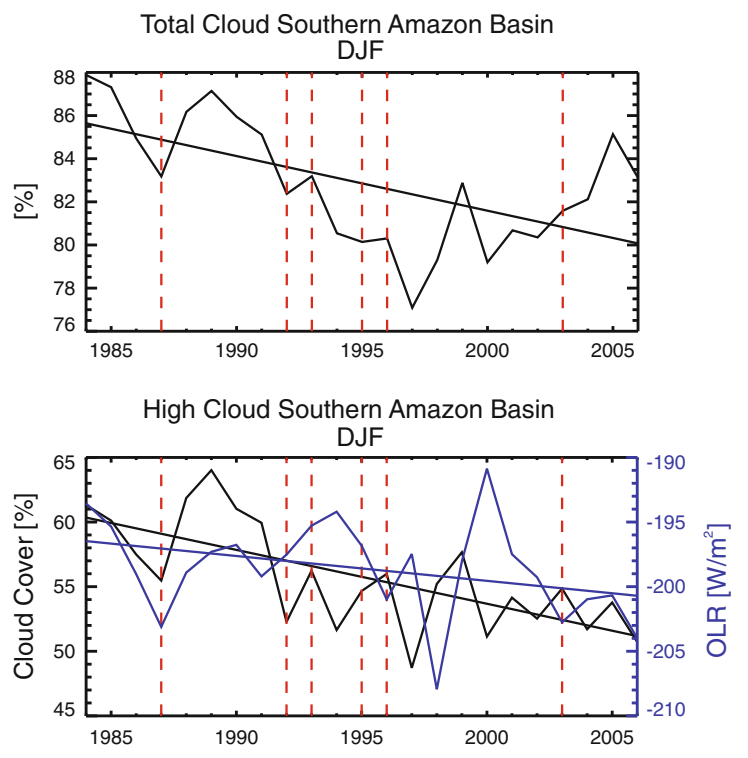

reposition according to ISCCP D2 data set documentation (available at http://isccp.giss.nasa.gov/index.html). Solid lines represent statistically significant trend at the 5\% level according to the MannKendall test with Sen's statistic (Sen 1968) 
To verify if changes in ISCCP high clouds are consistent with changes in OLR, monthly NOAA interpolated OLR is used. Since OLR includes changes from all type of clouds, water vapor, and surface temperatures, only values lower than $240 \mathrm{~W} / \mathrm{m}^{2}$ are considered in order to be consistent with ISCCP high clouds. An OLR value of $240 \mathrm{~W} / \mathrm{m}^{2}$ is an appropriate threshold for detecting deep convection (Murakami 1980; Lau and Chan 1983). Figure 2 shows domain averaged OLR over both northern and southern Amazon for the seasons with the largest changes in high clouds. In general, reduction in high clouds is consistent with a statistically significant increase in OLR for both DJF and SON seasons on decadal scale. The spatial pattern of OLR changes (not shown) agrees with that for high clouds (Fig. 1). The general consistency between these two fields measured by different satellite-born instruments suggests that the change in high clouds is unlikely an artifact of satellite measurement biases.

The interannual variations of the SON OLR over the northern Amazon agree with those of high clouds, except during 1997. DJF OLR averaged over the southern Amazon is out of phase with high clouds during some years. This discrepancy is presumably caused by insufficient diurnal sample of the OLR. During the wet season (DJF) in the southern Amazon, convection is contributed by two different types of clouds associated with different largescale atmospheric circulation (Rickenbach et al. 2002). These two convective types have different diurnal cycles (Rickenbach 2004). Interannual variations of the largescale circulation can alter the diurnal cycle of the convection over Southern Amazon. OLR daily value is derived from two measurements at a 12-h interval, whereas the ISCCP daily value is computed from eight measurements at 3-h interval. Thus, the monthly average of the daily OLR would be different from that averaged from the daily ISCCP high cloud amount even for a moderate change in diurnal cycle.

Another possible cause for this discrepancy relies on the fact that NOAA OLR measurements (broad band channel) are sensitive to atmospheric temperatures, water vapor, and the presence of clouds, while the ISCCP infrared channel is within the atmospheric window spectra, mainly sensitive to clouds. Then changes in atmospheric temperatures and water vapor could induce differences in OLR and high clouds measurements.

Several previous studies suggested that the DJF rainfall (either measured by station reported value or OLR estimated) probably increased over the Amazon basin (Chu et al. 1994; Chen et al. 2001). These seemingly different results from ours are due to use of different geographic domain and periods of analysis. For example, Chu et al. (1994) show a general decrease in DJF OLR during the period $1974-1990$ over the region $0-5^{\circ} \mathrm{N}$ and $78^{\circ} \mathrm{W}-70^{\circ} \mathrm{W}$, which is outside the domains considered in this study. ISCCP high clouds and NOAA OLR averaged over this region during DJF (not shown) indicate decreasing OLR and increasing high clouds, consistently with the increasing rainfall reported in their study.

Chen et al. (2001) reported an increase of precipitation over the Amazon from 1958-1977 to $1978-1998$ for a geographic domain $\left(15^{\circ} \mathrm{S}-15^{\circ} \mathrm{N}, 70^{\circ} \mathrm{W}-50^{\circ} \mathrm{W}\right)$ that is significantly larger than that used in this study. Since changes in high clouds during DJF are negative over the southern domain and insignificant with slightly positive trend over the northern domain (Fig. 1e), the cloud change averaged over the region considered in their study becomes insignificant for the period 1984-2007. We have compared OLR and high clouds variations with results of Chen et al. (2001) for the period of 1984-1996, when ISCCP data overlaps with their second analysis period. The results show negative changes in OLR over the southern Amazon before the mid-90s, consistently with the increasing rainfall reported by Chen et al. (2001). The increase of OLR and decrease of high clouds mainly occurred after the mid-90s over the Amazon, especially over the southern domain.

Considering the relatively short analysis period in this study, we have tested the sensitivity of the trends of the high clouds and OLR to different time periods within 1984-2007 (not shown). Results indicate that the spatial pattern of changes reported in Fig. 1 remains generally the same.

\subsection{Changes in surface temperature and humidity}

Table 1 shows seasonal trends during 1984-2005 for temperature, specific humidity, and relative humidity from

Table 1 Seasonal trends for surface data from Dai (2006) and VIMT from NCEP-NCAR reanalysis averaged over northern and southern Amazon (see geographical location in Fig. 1)

\begin{tabular}{lrrrr}
\hline & DJF & MAM & \multicolumn{1}{c}{ JJA } & \multicolumn{1}{c}{ SON } \\
\hline Northern Amazon & & & & \\
$q(\mathrm{~g} / \mathrm{kg})$ & 0.24 & 0.00 & -0.15 & -0.11 \\
RH $(\%)$ & -1.19 & 1.22 & $\mathbf{- 4 . 0 5}$ & $\mathbf{- 4 . 9 2}$ \\
$T\left({ }^{\circ} \mathrm{C}\right)$ & $\mathbf{0 . 6 8}$ & 0.00 & $\mathbf{0 . 5 2}$ & $\mathbf{1 . 0 1}$ \\
VIMT (mm/day) & 0.85 & $\mathbf{1 . 8 9}$ & $\mathbf{- 1 . 6 0}$ & $\mathbf{- 1 . 8 3}$ \\
Southern Amazon & & & & \\
$q(\mathrm{~g} / \mathrm{kg})$ & $\mathbf{0 . 8 2}$ & $\mathbf{0 . 5 2}$ & -0.39 & -0.09 \\
RH $(\%)$ & $\mathbf{1 . 7 0}$ & $\mathbf{2 . 5 5}$ & -0.14 & -2.06 \\
$T\left({ }^{\circ} \mathrm{C}\right)$ & $\mathbf{0 . 5 3}$ & 0.46 & $\mathbf{0 . 6 6}$ & 0.45 \\
VIMT (mm/day) & $\mathbf{1 . 2 4}$ & -0.42 & $\mathbf{- 0 . 9 7}$ & -0.42 \\
\hline
\end{tabular}

Values represent the total change in each variable during 1984-2005 (1984-2007 for VIMT). Values in bold are statistically significant at the 5\% level according to the Mann-Kendall test with Sen's statistics (Sen 1968) 
surface station data described by Dai (2006). Relative humidity decreases for June-July-August (JJA) and SON over both northern and southern Amazon. This decrease is more highly correlated with warmer surface temperatures than with declining specific humidity (see Table 1). Significant increase of surface temperature is also observed by Malhi and Wright (2004). Warmer surface temperatures over the Amazon are not purely due to increases in solar SW radiation. Observations have shown that the change of daytime temperature is primarily controlled by changes of surface solar radiation and wetness in the Amazon, whereas change of nighttime temperature is primarily influenced by water vapor and other greenhouse gasses.

The decrease in relative humidity over the Amazon basin is consistent with the observed decrease in cloudiness over the region. Radiosonde data from the University of Wyoming show reductions in atmospheric buoyancy over southern Amazon (not shown), consistent with reductions in atmospheric instability over the region.

\subsection{Possible causes for changes in cloudiness over the Amazon}

\subsubsection{Changes in vegetation and land use}

Whether changes in vegetation and land use affect cloudiness over tropical forests is explored by comparing the pattern of decreasing cloudiness (Fig. 1) and that of deforestation available in literature. Results from World Wildlife Fund (WWF) published by BBC News (http:// news.bbc.co.uk/2/hi/americas/7360258.stm) indicate that deforested regions are localized over the southern edge of the Amazon during 1970-1997, but a northward migration is observed during 1998-2006. These findings suggest that southern and southeastern Amazon domains are more affected by recent deforestation while northern Amazon remains less affected by land use. Studies by Drigo and Marcoux (1999) also show that the southern Amazon experienced more deforestation than the northern region during the period 1980-1990 (http://www.fao.org/sd/ wpdirect/WPan0030.htm). The reductions in cloudiness shown in Fig. 1 occurred over the entire Amazon, at a much larger spatial scale compared to that of the deforestation. Thus, changes in vegetation and land use cannot be the primary contributors for the observed large-scale changes in cloudiness over the Amazon forests.

\subsubsection{Links to decadal changes over the tropical Pacific and Atlantic Oceans}

Most of the high clouds detected by ISCCP are optically thick cirrus clouds produced by deep tropospheric convection (Rossow et al. 1996). Thus, this investigation will focus on understanding the causes for decrease of convection and rainfall over the Amazon basin. Many previous studies have shown a clear correlation between changes of convection and moisture transport and interannual SSTA in Pacific or Atlantic oceans. Changes in the mid-lower troposphere VIMT, which are determined independently from cloud observations, are examined to verify changes of cloudiness.

Table 1 shows a statistic significantly decrease of VIMT during JJA and SON over northern Amazon JJA over southern Amazon, which is consistent with the decrease of high cloudiness independently detected by the ISCCP, during the dry and transition seasons (Fig. 1). To determine whether these changes are linked to external SST forcing, composite changes of high clouds for positive $(>1 \sigma)$ and negative phases $(<-1 \sigma$; see Sect. 2$)$ are calculated. The number of events in both phases for the different indices of SST variability considered is shown in Table 2. Statistical significance of the difference between both composites is tested using a bootstrap test (Efron 1979).

Since ENSO-related changes could be dominant at decadal scales during the period considered here (1984-2007), these contributions are removed from all the SST variability indices. This is done by subtracting the temporal variations that are correlated with the Niño index as determined by the linear regression from the original time series for any specific SST index (e.g., AMO, PDO, etc.). The composites are obtained based on the residual time series of these indices. We found that, after ENSO influence is removed, changes in cloudiness due to PDO and DMI become insignificant for all the seasons, suggesting that the effects of PDO and IOD on cloudiness over the Amazon cannot be separated from that of ENSO.

Although AMO signal is correlated with the tropical Atlantic SSTG, previous studies suggest that it may be physically independent from the SST changes in the

Table 2 Number of years with statistically significant at 5\% level positive (PP) and negative (NP) phases for the SST variability indices considered here

\begin{tabular}{|c|c|c|c|c|c|c|}
\hline & \multicolumn{2}{|c|}{ DJF } & \multicolumn{2}{|c|}{ MAM } & \multicolumn{2}{|c|}{ SON } \\
\hline & NP & $\mathrm{PP}$ & NP & $\mathrm{PP}$ & NP & $\mathrm{PP}$ \\
\hline AMO & 5 & 6 & 5 & 3 & 5 & 5 \\
\hline PDO & 3 & 4 & 5 & 5 & 5 & 5 \\
\hline Western Pacific WPA & 4 & 4 & 4 & 4 & 3 & 4 \\
\hline DMI & 5 & 2 & 4 & 5 & 3 & 4 \\
\hline Atlantic SSTG & 4 & 1 & 3 & 4 & 4 & 5 \\
\hline Atlantic SSTG (No AMO) & 3 & 3 & 2 & 2 & 3 & 2 \\
\hline
\end{tabular}

ENSO contributions are removed. Positive (negative) phases are selected as those years with an index value above (below) $1 \sigma$ of its climatological value. Statistical significance is tested using a boostrap test (Efron 1979) 
southern tropical Atlantic (Chang et al. 2006). To clarify the physical processes, especially that of the AMO behind the influence of the tropical Atlantic SSTG, its correlation with the cloudiness over the Amazon with and without AMO is analyzed.

The development of convection over the southern Amazon and its further migration to the northern Amazon are part of a characteristic cycle over the Amazon rainforest that produces seasonal differences between both regions: (i) DJF corresponds to the peak in rainfall over the southern Amazon, although there are still heavy precipitation events over this region during MAM, (ii) rainfall over the northern Amazon has its peak during MAM, and (iii) SON corresponds to the transition between dry and wet conditions over the southern Amazon. We organize our analysis based on these seasonal patterns and our discussion will focus on the DJF, MAM and SON seasons when significant decrease of cloudiness has been detected.

\subsubsection{DJF Figure 3 shows DJF linear trends of SSTA} and correlations between detrended SSTA and detrended domain average high cloud for (a) northern and (b) southern Amazon. There is a general warming over the equatorial oceans, except over south tropical Atlantic, where cooling is observed. Correlation between SSTA and high clouds for both domains shows a strong link to the
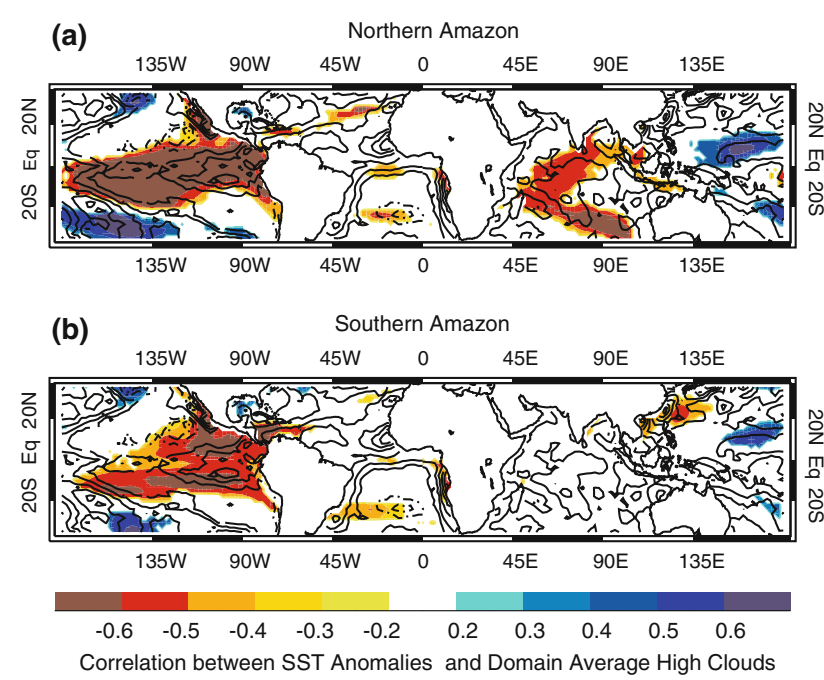

Fig. 3 DJF correlations (color shades) between detrended SST anomalies from NOAA-CDC and detrended domain average high level clouds over a northern Amazon and b southern Amazon. Correlations shown are statistically significant at the 5\% level based on Monte Carlo test and the spatial patterns shown are also statistically significant at 5\% level (Livezey and Chen 1983). Contours represent trends in SST anomalies during 1984-2007. Trends shown are statistically significant at the 5\% level according to the Mann-Kendall test with Sen's statistic (Sen 1968). Contours are plotted with interval of $0.1^{\circ} \mathrm{C}$ per decade. Solid (dashed) contours represent warm (cold) SST anomalies central and eastern Pacific SSTs, suggesting that change in high cloudiness in the Amazon is especially sensitive to SST changes in these oceanic regions during austral summer. This relationship is consistent with the well documented relationship between rainfall change over the northern Amazon and SSTA (Marengo 1992). In addition, Fig. $3 \mathrm{a}$ also suggests that warmer temperatures over the Indian Ocean are linked to decreasing high clouds over the northern Amazon. The correlation between changes in high clouds in the southern Amazon and SSTA in the equatorial central and eastern Pacific is stronger than that estimated based on rain gauge data shown in previous studies (e.g., Marengo 1992).

Both WPA and IOD can be affected by ENSO. To determine to what extend they are correlated with the change of the cloudiness over the Amazon independently of ENSO, ENSO related SSTA changes from WPA and IOD are removed. The result shows that only WPA is still significantly correlated to cloud changes during DJF over northern Amazon (-0.51), i.e., the western Pacific warm pool expansion is correlated with a decrease of high cloudiness over that region.

Composite analyses for this season indicate that high clouds over the Amazon decrease during the western Pacific warm pool expansion events (not shown). To determine whether these changes are an artifact of ENSO contribution to increasing WPA, changes of WPA index that are correlated to ENSO index are removed. Since warm pool expansion mainly occurred in the central Pacific, ENSO influence on WPA is removed based on its regression with the Niño 4 index, i.e., (SSTs averaged over the region over the western Pacific bounded by $160^{\circ} \mathrm{E}-$ $150^{\circ} \mathrm{W}$ and $5^{\circ} \mathrm{S}-5^{\circ} \mathrm{N}$ ). Significant changes in high clouds between the positive and negative phases of WPA are still retained even after the removal of the ENSO influence (Fig. 4).

3.3.2.2 MAM Figure 5 shows positive SSTG (warming on the north side and cooling on the south side of the equator) in the tropical Atlantic and a strong warming of SST in the east Pacific during MAM season. A decrease in high clouds over the southern Amazon is correlated with these increases of SST. Changes in high clouds over the northern Amazon are weak (Fig. 1f), thus no significant correlation with SST anomalies are detected (not shown).

Atlantic SSTG is dominated by the Atlantic dipole mode (Nobre and Shukla 1996), which has the strongest variability during MAM, which is controlled by AMO and SST anomalies in the southern Atlantic Ocean. Composite changes of high clouds using AMO index (Fig. 6) suggest a significant decrease of high cloudiness in Amazon during positive AMO phases. The dipole pattern of the high cloud change over the tropical Atlantic resembles the northward 


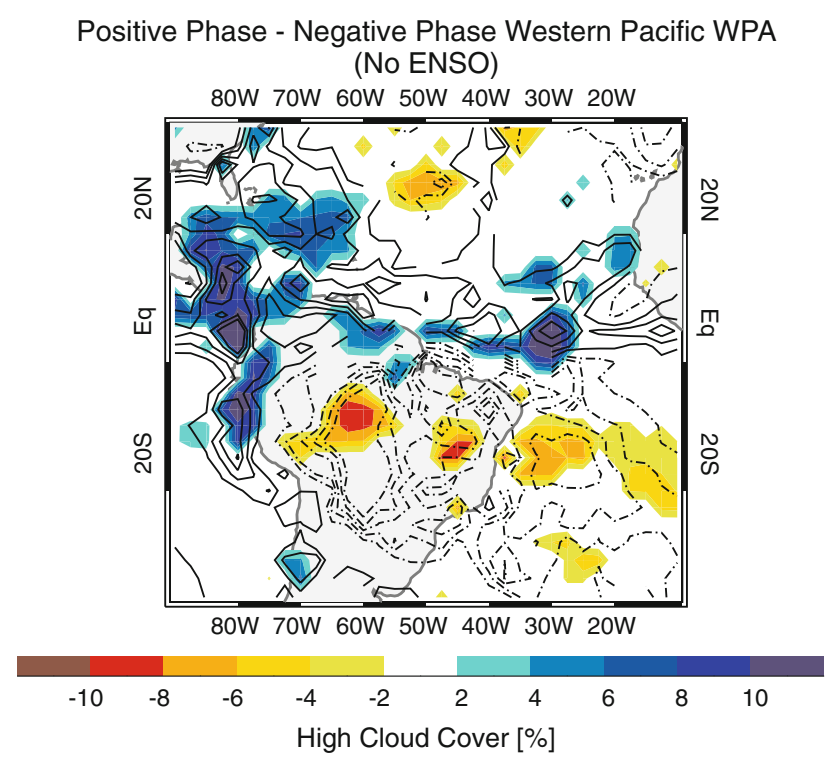

Fig. 4 Composite high cloud difference for positive and negative phases of western Pacific WPA (No ENSO) for DJF. Statistical significance for difference is tested using a bootstrap test (Efron 1979) at $5 \%$ level. Contours indicate trends in high cloud anomalies statistically significant at the 5\% level according to the Mann-Kendall test with Sen's statistic (Sen 1968). Solid (dashed) lines represent increasing (decreasing) clouds. Contours are plotted each $1 \%$ per decade

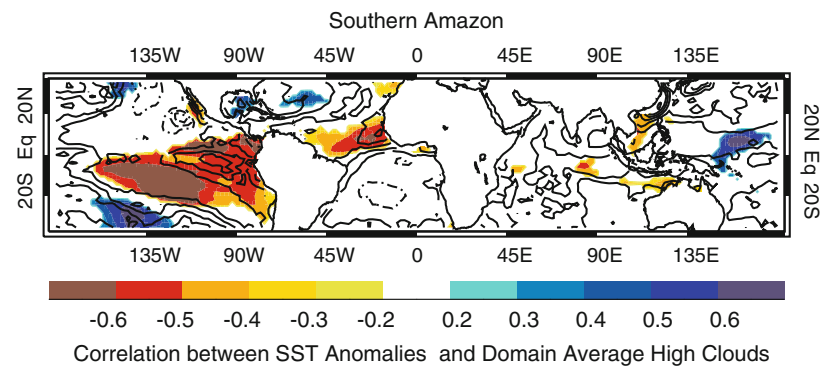

Fig. 5 Same as Fig. 3 but for MAM

shift of the Atlantic ITCZ associated with positive phase of the Atlantic meridional dipole mode (e.g., Nobre and Shukla 1996; Chiang et al. 2000). The spatial pattern of this cloudiness change also resembles that for the trend of high cloud change. Composites shown in Fig. 6 are statistically significant according to the bootstrap test (Efron 1979).

Composites using Atlantic SSTG (not shown) also indicate reductions in high cloudiness in the southern Amazon when this gradient increases. However, after the removal of AMO, the correlation between changes of high cloudiness over the Amazon and the Atlantic SSTG becomes insignificant. Thus, the decrease of high clouds during MAM in the southern Amazon is consistent with the circulation changes associated with positive phase of AMO. Significant correlation between high cloud change

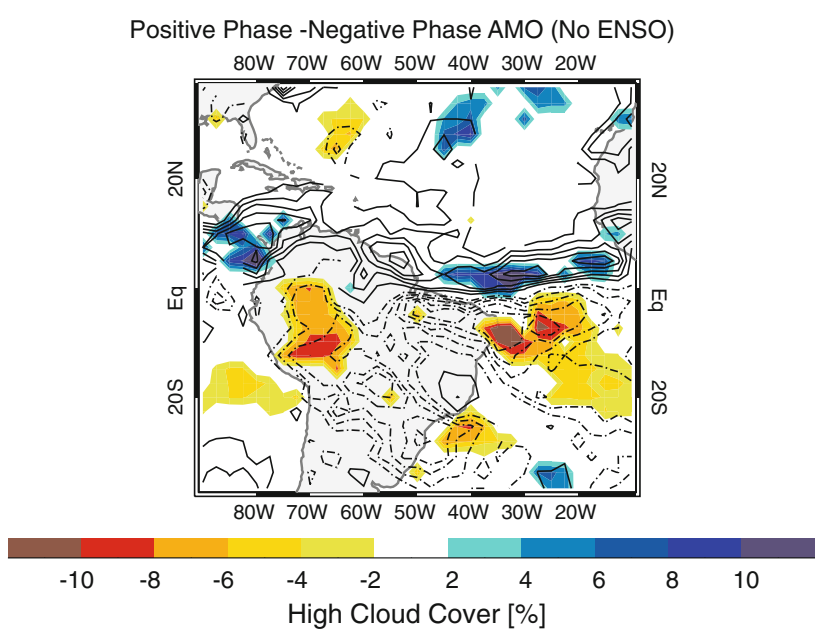

Fig. 6 Composite high cloud difference for positive and negative phases of AMO (No ENSO) for MAM. Statistical significance for difference is tested using a bootstrap test (Efron 1979) at 5\% level. Contours indicate trends in high cloud anomalies statistically significant at the 5\% level according to the Mann-Kendall test with Sen's statistic (Sen 1968). Solid (dashed) lines represent increasing (decreasing) trends. Contours are plotted with interval of $1 \%$ per decade

in the southern Amazon and AMO (not shown) also support this result.

As shown in Fig. 5, high clouds over southern Amazon are negatively correlated with SSTA over the eastern Pacific during MAM. This pattern is observed even after the east Pacific ENSO influence, as represented by Niño 3 index, is removed (not shown). Thus, the link between eastern Pacific warming and reduced high cloudiness over the southern Amazon appears to be statistically independent from ENSO.

3.3.2.3 SON During this season, decrease of high clouds in the northern Amazon is correlated with warmer SST in the central Pacific and cooler SST in the southern tropical Atlantic (Fig. 7). Decrease of high clouds in the southern Amazon, which is weaker than that in the northern Amazon, is correlated with cooler SST in the southern tropical Atlantic (Fig. 7b).

Composites differences in high clouds between the positive and negative Atlantic SSTG is statistically significant, even when the AMO contributions are removed (Fig. 8a). Because AMO is primarily correlated with SSTA in the northern tropical Atlantic, the above result confirms the correlation between high clouds and SSTA in the southern tropical Atlantic shown in Fig. 7. Figure 8a shows that high clouds decrease basin wide, especially in the western and central northern and southern Amazon, when strong positive Atlantic SSTG occurs due to cooler SSTs in the southern tropical Atlantic. The areas and pattern of decreasing clouds match the trend of decreasing high 

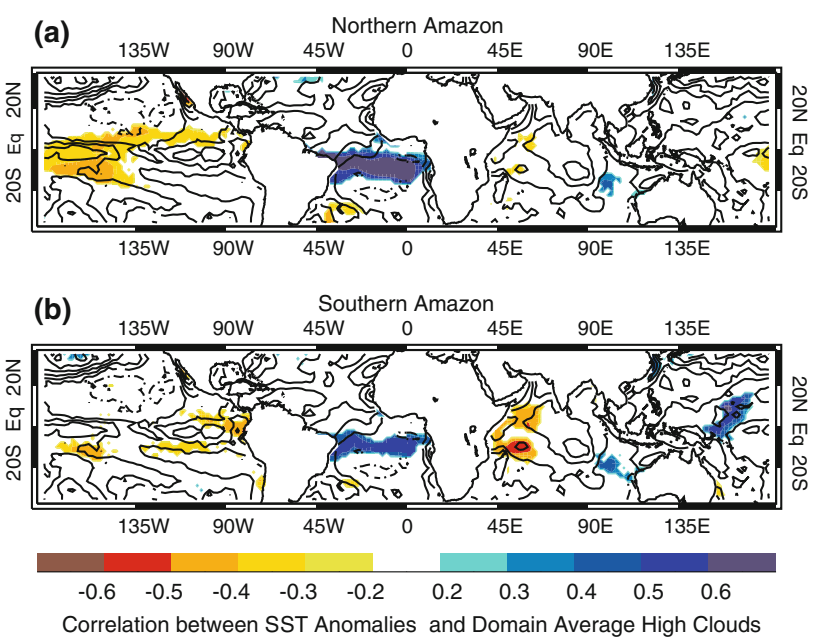

Fig. 7 Same as Fig. 3 but for SON

clouds in the western and central Amazon, suggesting that a change toward cooler SST in the southern tropical Atlantic probably contributes to the decrease of high clouds in this region.

Reductions in high clouds over the northeastern Amazon and the Nordeste region are also observed when the western Pacific warm pool expands during SON (see Fig. 8b). This is consistent with the correlation between high clouds changing in the northern Amazon and SSTA in the tropical central Pacific shown in Fig. 7a. Figure 8b suggests that the expansion of the Pacific warm pool probably contributes to the decrease of high clouds in the western tropical South America. Results obtained from correlation analysis are consistent with those of composite analysis shown in Fig. 8 (the correlation coefficients over the region vary from -0.5 to -0.6 for Atlantic SSTG and from -0.3 to 0.4 for WPA; not shown).

\subsubsection{The underlying dynamic processes}

What processes are responsible for the observed relationship between changes of cloudiness and aforementioned ocean-atmosphere variability? Previous studies suggest two mechanisms: (i) anomalous change of direct thermal circulation either zonally or meridionally (e.g., Moura and Shukla 1981; Chiang and Sobel 2002; Neelin et al. 2003) and (ii) change in planetary wave trains from the tropical central Pacific to South America (e.g., Kalnay et al. 1986; Fu et al. 2001; Liebmann et al. 2004). The former would show clearly in seasonal mean correlation between changes in moisture transport and high clouds, whereas the latter would be dominated by transient disturbances instead of by seasonal mean anomalies.

The analysis discussed above and correlations between VIMT and SSTA (not shown) suggest that changes of moisture transport over the northern Amazon are well correlated to SST changes but this relationship is very weak for the southern domain. This suggests that a decrease in moisture transport has likely contributed directly to the decrease of cloudiness in the northern Amazon (as previously suggested by Wang 2002; Yoon and Zeng 2010), but not necessarily in the southern Amazon. Other dynamic mechanisms need to be explored.

Planetary wave trains link anomalies of convection in the SPCZ to that of the SACZ (Kalnay et al. 1986; Grimm and Silva Dias 1995; Nogues-Paegle and Mo 1997; Lenters and Cook 1995; Fu et al. 2001). The latter is anti-correlated with rainfall variability in the Amazon (Liebmann et al. 2004). These anomalous wave trains could alter the equator-ward incursion of the extratropical synoptic disturbances, thus influencing cloudiness. To test this hypothesis, composites for differential streamfunction at 0.22 sigma
Fig. 8 Composite high cloud difference for positive and negative phases of a Atlantic SSTG (No AMO, No ENSO) and b western Pacific WPA (No ENSO) for SON. Statistical significance for difference is tested using a bootstrap test (Efron 1979) at 5\% level.

Contours indicate trends in high cloud anomalies statistically significant at the $5 \%$ level according to the Mann-Kendall test with Sen's statistic (Sen 1968). Solid (dashed) lines represent increasing (decreasing) trends. Contours are plotted with interval of $2 \%$ per decade (a) Positive Phase - Negative Phase Atlantic SSTG (No AMO, No ENSO)

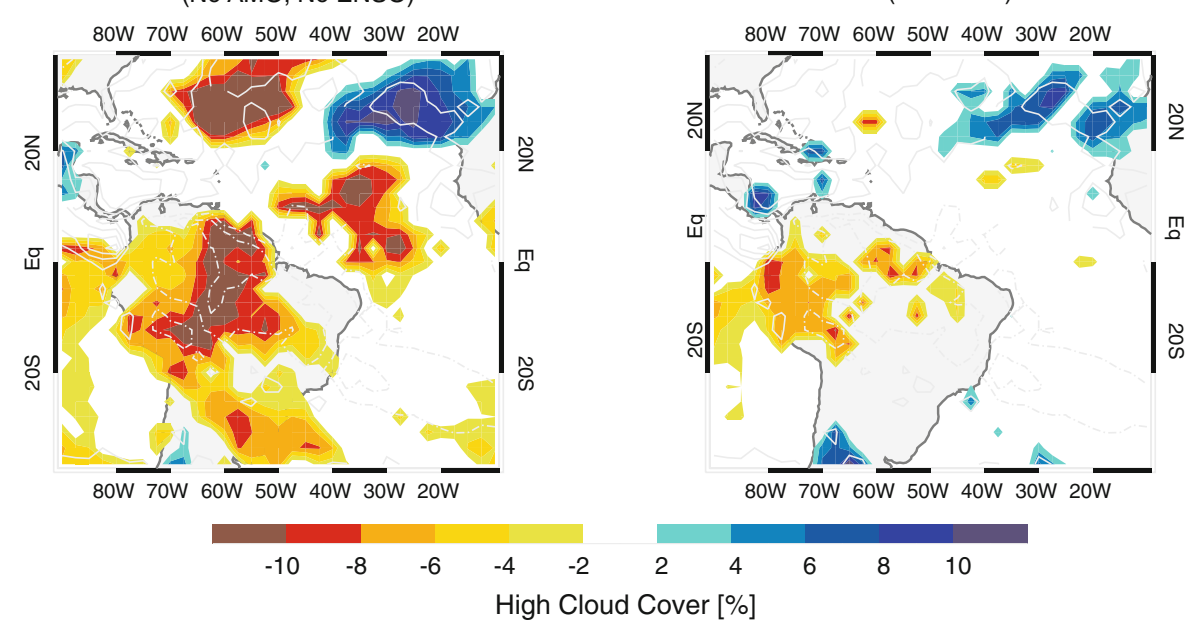


level ( $\sim 200 \mathrm{hPa}$ ) between years with southern Amazon average high clouds above and below 1 standard deviation of the climatology were estimated. The difference was tested using a bootstrap test (Efron 1979). The number of years with southern Amazon average high clouds above/ below $1 \sigma$ is six/four during DJF and three/five during SON from 1984 to 2007.

Figure $9 \mathrm{a}, \mathrm{b}$ shows trends in the 0.22 sigma level streamfunction during the period 1984-2007 for DJF and SON, respectively. Results indicate a stronger cycloneanticyclone-cyclone tripole structure over the South Pacific-South America region, especially during SON, typically observed in PSA wave trains (Fu et al. 2001). The relationship between upper tropospheric streamfunction and decreasing high clouds over southern Amazon are shown in Fig. 9c, d. Blue (red) colors indicate statistically significant strengthening in cyclonic (anticyclonic) circulation when high clouds are reduced over the southern Amazon. Composites for DJF and SON (Fig. 9c, d) show that the structure associated to PSA wave trains is enhanced for those years when high cloudiness over the southern Amazon is reduced.
The association of wave trains and oceanic variability over the Pacific has been previously established by Kalnay et al. (1986), Fu et al. (2001) and Liebmann et al. (2009) for seasonal and interannual scales. In particular, when SSTs in the central-eastern equatorial Pacific Ocean are warm, the anomalous wave-train from the tropical center Pacific to the extratropical Southeastern Pacific to the South America tends to enhance the SACZ. The latter tends to suppress convection over the southwestern Amazon (Nogues-Paegle and Mo 1997).

Our result suggests that reduction in high clouds over the southern region of the Amazon rainforest on multidecadal decadal scale is likely linked to stronger wave trains in the south Pacific and South American sector, which in turn is associated to SST changes over the Pacific.

\section{Implications to the observed increase of growth rate over the Amazon forests}

Statistically significant increase in biomass and net primary productivity (NPP) over the Amazon forest has been

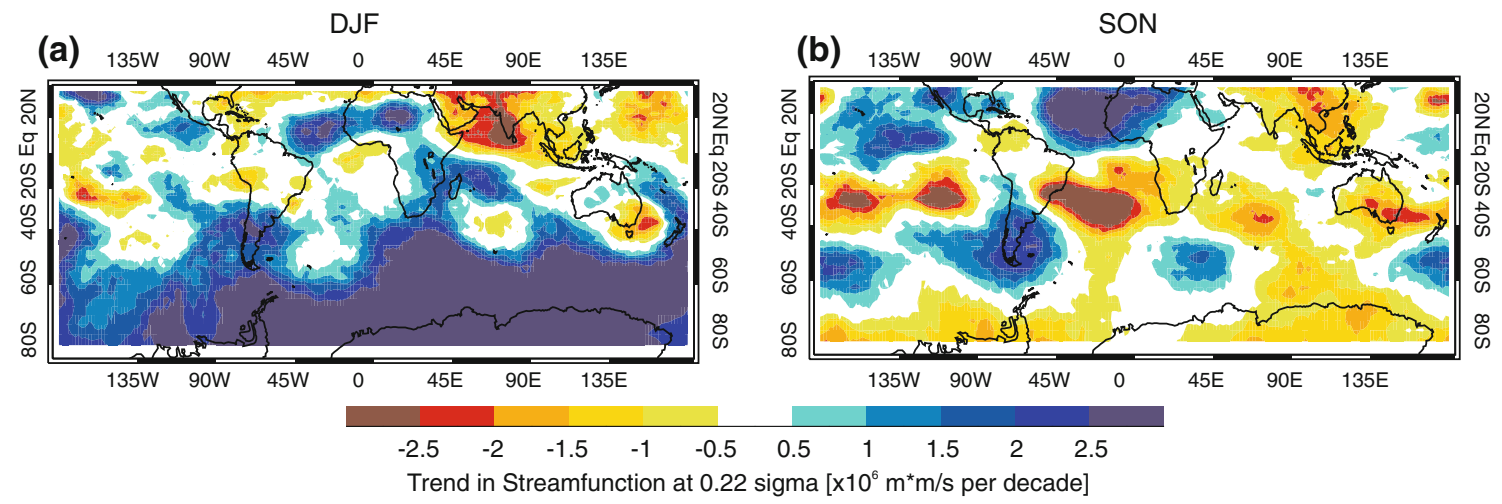

(c)

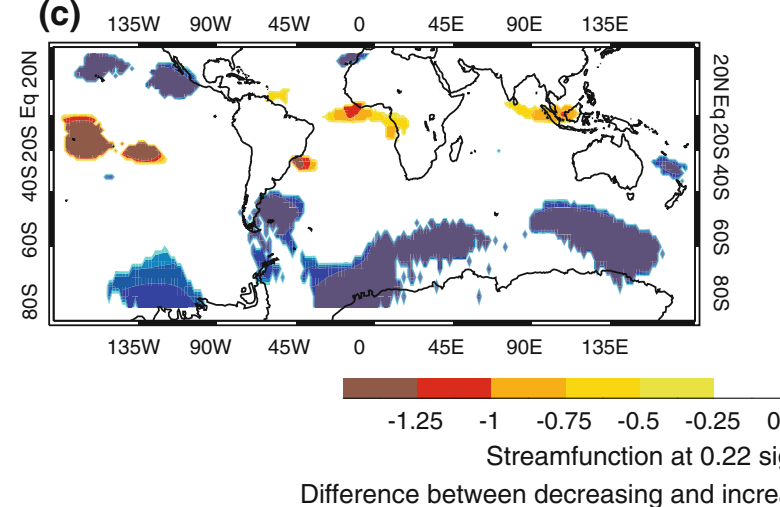

(d)

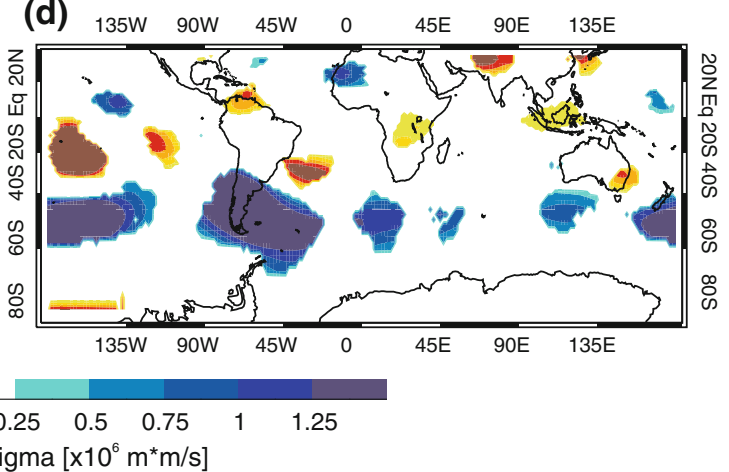

Fig. 9 Trends in streamfunction during a DJF and b SON. Differences between $-1 \sigma$ decrease and $1 \sigma$ increase of high clouds events in the southern Amazon for streamfunction at 0.22 sigma level ( $\sim 200 \mathrm{hPa}$ ) during $\mathbf{c}$ DJF and d SON. Statistical significance for difference is tested using a bootstrap test (Efron 1979) at 5\% level. Trends are statistically significant at the 5\% level according to the Mann-Kendall test with Sen's statistic (Sen 1968) 
documented (Phillips et al. 1998; Nemani et al. 2003; Lewis et al. 2004a; Laurance et al. 2004). Phillips et al. (1998) found a widespread increase in the biomass of neotropical forests over recent decades. They suggest possible mechanisms that may explain this change, including (i) a response to continental-scale cyclical climate change (e.g., ENSO), (ii) response to widespread disturbance, either natural (e.g., volcano aerosols) or anthropogenic (e.g., increasing atmospheric $\mathrm{CO}_{2}$ ), (iii) enhanced forest productivity due to a secular change in climate or increased nutrient availability (due to increased $\mathrm{N}$ and $\mathrm{P}$ deposition from Saharan dust and biomass burning), and (iv) $\mathrm{CO}_{2}$ fertilization.

Increasing atmospheric $\mathrm{CO}_{2}$ has received the most of attention among the aforementioned potential causes (Lewis et al. 2004a, b; Laurance et al. 2004). However, Nemani et al. (2003) report that the increase in NPP, at least during 1982 and 1999, is too large to be explained by $\mathrm{CO}_{2}$ fertilization alone. They further suggest that an increase in solar radiation in these radiation-limited forests is the most likely explanation for the increasing tropical NPP. The results of this study show a multi-decadal scale decrease of cloudiness and an increase of downward solar SW radiation at the surface over the Amazon. Thus, our results imply that an increase of surface solar radiation and reduced cloudiness, forced by decadal scale variation of SST changes in the tropical Pacific and Atlantic, would contribute to the increase in forest growth rate, as proposed by Nemani et al. (2003). Since AMO has begun to change toward a negative phase in recent years, whether or not the forest growth rate in the coming decade would change will provide us an opportunity to clarify the relative roles between $\mathrm{CO}_{2}$ fertilization and surface solar radiation change.

\section{Conclusions}

Increasing SW down-welling radiation and decreasing total clouds cover over Amazon forests are shown using the ISCCP cloud and SW radiation data during the period of 1984-2007. This change in total cloudiness, mainly resulting from a decrease of high clouds, is not caused by changes in satellite viewing angle of the geostationary satellites, or by deforestation and land use, rather it is consistent with changes of the large-scale circulation determined independently from the cloud observations. The changes of cloudiness are consistent with rising temperatures over this forest shown by the surface meteorological station data, a decrease of vertically integrated moisture transport between 1,000 hPa and $600 \mathrm{hPa}$ levels shown by the NCEP-NCAR reanalysis, and the drying of the middle-lower troposphere over the Amazon based on the upper-air meteorological data.
Although high clouds decrease in all seasons except for the dry season (JJA), the spatial patterns and their links to the decadal oceanic variability vary seasonally. During DJF and MAM, high clouds decrease in southern Amazon. Such a change is primarily linked to the expansion of the tropical Pacific warm pool during DJF and to the AMO and eastern Pacific SSTA during MAM. During SON, the decrease of cloudiness occurs in both the northern and southern Amazon. The change of clouds in the western Amazon is linked to cooler SSTs in the southern tropical Atlantic, whereas the change of clouds in the northeastern Amazon and Nordeste region are mainly linked to the expansion of the western Pacific warm pool.

What could cause the decrease of high clouds over the Amazon basin? Reduction of the high clouds over the northern Amazon is consistent with an enhanced subsidence, which compensates enhanced rising motion in the northern equatorial Atlantic and the Nordeste region (as shown by Moura and Shukla 1981; Chiang and Sobel 2002; Neelin et al. 2003). This suggests that changes in direct thermal circulation, which could reduce moisture transport and stabilize the upper troposphere are probably responsible for the decrease of high clouds in that region. By contrast, changes in moisture transport and low-level anomalous wind in the southern Amazon are not well correlated to the SSTA. Further analyses suggest that anomalous Pacific-South American planetary wave trains may reduce high clouds. It has been shown by previous studies that these wave trains are linked to SST variability over the Pacific Ocean. Whether the observed changes are part of natural climate variability or due to anthropogenic influences needs to be investigated.

The decrease of cloudiness over the Amazon and the resultant increase of solar SW radiation since 1984 support the hypothesis that increasing surface solar radiation contribute to the increasing forest growth rate over the Amazon, as proposed by Nemani et al. (2003).

The period of analysis considered in this study is too short to fully assess the impact of multi-decadal SST variability on change of cloudiness over the Amazon. Thus, whether the change of cloudiness and their underlying causes found in this study adequately represent multidecadal variations or trend has to be tested when long period of data become available in future.

Acknowledgments This work was supported by the National Science Foundation ATM 0203761 grant, the National Aeronautics and Space Administration Terra, Aqua and ACRIMSAT NNG04GK90G project, and the NOAA Climate Prediction and Program for the Americas Project. The authors thank Drs. Aiguo Dai, William Rossow, and Amato Evan for providing the surface station data and helpful advices on ISCCP data. We also thank the two anonymous reviewers for their insightful comments and Nicole Smith-Downey and Jud Partin for their help during the edition of this manuscript. 
Open Access This article is distributed under the terms of the Creative Commons Attribution Noncommercial License which permits any noncommercial use, distribution, and reproduction in any medium, provided the original author(s) and source are credited.

\section{References}

Artaxo P, Martins JV, Yamasoe MA, Procópio AS, Pauliquevis TM, Andreae MO, Guyon P, Gatti LV, Leal AMC (2002) Physical and chemical properties of aerosols in the wet and dry seasons in Rondônia, Amazonia. J Geophys Res 107(20):8081. doi:10. 1029/2001JD000666

Campbell GG (2004) View angle dependence of cloudiness and the trend in ISCCP cloudiness. http://ams.confex.com/ams/ pdfpapers/79041.pdf

Chan SC, Behera SK, Yamagata T (2008) Indian Ocean Dipole influence on South American rainfall. Geophys Res Lett 35:L14S12. doi:10.1029/2008GL034204

Chang P, Fang Y, Saravanan R, Ji L, Seidel H (2006) The cause of the fragile relationship between the Pacific El Niño and the Atlantic Niño. Nature 443:324-328

Chen TC, Yoon JH, St. Croix KJ, Takle ES (2001) Suppressing impacts of the Amazonia deforestation by the global circulation change. Bull Am Meteor Soc 82:2209-2216

Chen J, Carlson BW, Del Genio AD (2002) Evidence for Strengthening of the Tropical General Circulation in the 1990s. Science 295:838-841

Chiang J, Sobel A (2002) Tropical tropospheric temperature variations caused by ENSO and their influence on the remote tropical climate. J Clim 15:2616-2631

Chiang JCH, Kushnir Y, Zebiak SE (2000) Interdecadal changes in eastern Pacific ITCZ variability and its influence on the Atlantic ITCZ. Geophys Res Lett 27:3687-3690

Chu PS, Yu ZP, Hastenrath S (1994) Detecting climate change concurrent with deforestation in the Amazon Basin: which way has it gone? Bull Am Meteor Soc 75:579-583

Coe MT, Costa MH, Soares-Filho BS (2009) The influence of historical and potential future deforestation on the stream flow of the Amazon River-Land surface processes and atmospheric feedbacks. J Hydrol 369:165-174

Dai A (2006) Recent climatology, variability, and trends in global surface humidity. J Clim 19:3589-3606

Drigo R, Marcoux A (1999) Population dynamics and the assessment of land use changes and deforestation, Part 1. http://www.fao. org/sd/wpdirect/WPan0030.htm

Efron B (1979) Bootstrap methods: another look at the jackknife. Ann Stat 7:1-26

Enfield DB, Mestas-Nunez AM, Trimble PJ (2001) The Atlantic Multidecadal Oscillation and its relationship to rainfall and river flows in the continental U.S. Geophys Res Lett 28:2077-2080

Evan AT, Heidinger AK, Vimont DJ (2007) Arguments against a physical long-term trend in global ISCCP cloud amounts. Geophys Res Lett 34:L04701. doi:10.1029/2006GL028083

Fu R, Dickinson RE, Chen M, Wang H (2001) How do tropical sea surface temperatures influence the seasonal distribution of precipitation in the equatorial Amazon? J Clim 14:4003-4026

Gedney N, Cox PM, Betts RA, Boucher O, Huntingford C, Stott PA (2006) Detection of a direct carbon dioxide effect in continental river runoff records. Nature 439:835-838

Giannini A, Saravanan R, Chang P (2004) The preconditioning role of Tropical Atlantic Variability in the development of the ENSO teleconnection: implications for the prediction of Nordeste rainfall. Clim Dyn 22:839-855
Grimm AM, Silva Dias PL (1995) Analysis of tropical-extratropical interactions with influence functions of a barotropic model. J Atmos Sci 52:3538-3555

Gu L, Baldocchi DD, Wofsy SC, Munger JW, Michalsky JJ, Urbanski SP, Boden TA (2003) Response of a deciduous forest to the Mount Pinatubo eruption: enhanced photosynthesis. Science 299:2035-2038

Ichii K, Hashimoto H, Nemani R, White M (2005) Modeling the interannual variability and trends in gross and net primary productivity of tropical forests from 1982 to 1999. Glob Planet Change 48:274-286

Kalnay E, Mo KC, Paegle J (1986) Large-amplitude, shortscale stationary Rossby waves in the Southern Hemisphere: observations and mechanistic experiments to determine their origin. J Atmos Sci 43:252-275

Kalnay E, Kanamitsu M, Kistler R, Collins W, Deaven D, Gandin L, Iredell M, Saha S, White G, Woollen J, Zhu Y, Chelliah M, Ebisuzaki W, Higgins W, Janowiak J, Mo K, Ropelewski C, Wang J, Leetma A, Reynolds R, Jenne R, Joseph D (1996) The NCEP-NCAR 40-Year Reanalysis Project. Bull Am Meteor Soc 77:437-471

Kayano MT, Andreoli RV (2007) Relations of South American summer rainfall interannual variations with the Pacific Decadal Oscillation. Int J Climatol 27:531-540

Kerr RA (2000) A North Atlantic climate pacemaker for the centuries. Science 288(5473):1984-1986

Knight JR (2006) Climate impacts of the Atlantic Multidecadal Oscillation. Geophys Res Lett L17706. doi:10.1029/ 2006GL026242

Lau KM, Chan PH (1983) Short-term climate variability and atmospheric teleconnections from satellite-observed outgoing longwave radiation. I: simultaneous relationships. J Atmos Sci 40:2735-2750

Laurance WF, Oliveira AA, Laurance SG, Condit R, Nascimento HEM, Sanchez-Thorin AC, Lovejoy TE, Andrade A, D'Angelo S, Ribeiro JE, Dick CW (2004) Pervasive alteration of tree communities in undisturbed Amazonian forests. Nature 428(6979):171-175

Lenters JD, Cook KH (1995) Simulation and diagnosis of the regional summertime precipitation climatology of South America. J Clim 8:2988-3005

Lewis SL, Phillips OL, Baker TR, Lloyd J, Malhi Y, Almeida S, Higuchi N, Laurance WF, Neill DA, Silva JNM, Terborgh J, Torres-Lezama A, Vasquez-Martinez R, Brown S, Chave J, Kuebler C, Nufiez-Vargas P, Vinceti B (2004a) Concerted changes in tropical forest structure and dynamics: evidence from 50 South American long-term plots. Phil Trans Roy Soc (Lond) B 359(1443):421-436

Lewis SL, Malhi Y, Phillips OL (2004b) Fingerprinting the impacts of global change on tropical forests. Phil Trans Roy Soc (Lond) B 359(1443):437-462

Li W, Fu R (2004) Transition of the large-scale atmospheric and land surface conditions from the dry to the wet season over Amazonia as diagnosed by the ECMWF Reanalysis. J Clim 17:2637-2651

Liebmann B, Smith CA (1996) Description of a Complete (Interpolated) Outgoing Longwave Radiation Dataset. Bull Am Meteor Soc 77:1275-1277

Liebmann B, Kiladis GN, Vera CS, Saulo AC (2004) Subseasonal variations of rainfall in South America in the vicinity of the lowlevel jet east of the Andes and comparison to those in the South Atlantic convergence zone. J Clim 17:3829-3842

Liebmann B, Kiladis GN, Leila MV, Carvalho CJ, Vera CS, Bladé I, Allured D (2009) Origin of Convectively Coupled Kelvin Waves over South America. J Clim 22:300-315

Livezey RE, Chen WY (1983) Statistical field significance and its determination by Monte Carlo Techniques. Mon Wea Rev 111:46-59 
Malhi Y, Wright J (2004) Spatial patterns and recent trends in the climate of tropical rainforest regions. Phil Trans Roy Soc (Lond) 359:311-329

Mantua NJ, Hare SR, Zhang Y, Wallace JM, Francis RC (1997) A Pacific interdecadal climate oscillation with impacts on salmon production. Bull Am Meteor Soc 78:1069-1079

Marengo JA (1992) Interannual variability of surface climate in the Amazon basin. Int J Climatol 12:853-863

Marengo JA (2004) Interdecadal variability and trends of rainfall across the Amazon basin. Theor Appl Climatol 78:79-96

Marengo JA (2005) Characteristics and spatio-temporal variability of the Amazon River basin Mawater budget. Clim Dyn 24:11-22

Moura AD, Shukla J (1981) On the dynamics of droughts in northeast Brazil: Observations, theory and numerical experiments with a general circulation model. J Atmos Sci 38:2653-2675

Murakami T (1980) Empirical orthogonal function analysis of satellite-observed outgoing longwave radiation during summer. Mon Wea Rev 108:205-222

Myneni B, Yang W, Nemani RR, Huete AR, Dickinson RE, Knyazikhin Y, Didan K, Fu R, Negron Juarez R, Saatchi S, Hashimoto H, Ichii K, Shabanov NV, Tan B, Ratana P, Privette JL, Morisette JT, Vermote ET, Roy DP, Wolfe RE, Friedl MA, Running SW, Votava P, Saleous NZ, Devadiga S, Su Y, Salomonson VV (2007) Large Seasonal Swings in Leaf Area of Amazon rainforests. PNAS 104(12):4280-4283

Neelin JD, Chou C, Su H (2003) Tropical drought regions in global warming and El Niño teleconnections. Geophys Res Lett 30(24):2275. doi:10.1029/2003GL018625

Nemani R, Keeling CD, Hashimoto H, Jolly W, Piper S, Tucker C, Myneni R, Running S (2003) Climate-driven increases in Global Terrestrial Net Primary Production from 1982 to 1999. Science 300:1560-1563

Nobre P, Shukla J (1996) Variations of sea surface temperature, wind stress, and rainfall over the tropical Atlantic and South America. J Clim 9:2464-2479

Nogues-Paegle J, Mo KC (1997) Alternating wet and dry conditions over South America during summer. Mon Wea Rev 125: 279-291

Norris JR (2005) Multidecadal changes in near-global cloud cover and estimated cloud cover radiative forcing. J Geophys Res 110:D08206. doi:10.1029/2004JD005600

Phillips OL, Malhi Y, Higuchi N, Laurance WF, Nuñez VP, Vásquez RM, Laurance SG, Ferreira LV, Stern M, Brown S, Grace J (1998) Changes in the carbon balance of tropical forest: evidence from long-term plots. Science 282:439-442

Reynolds RW (1988) A real-time global sea surface temperature analysis. J Clim 1:75-86
Rickenbach TM (2004) Nocturnal cloud systems and the diurnal variation of clouds and rainfall in southwestern Amazonia. Mon Wea Rev 132:1201-1219

Rickenbach TM, Ferreira RN, Halverson J, Silva Dias MAF (2002) Modulation of convection in the southwestern Amazon basin by extratropical stationary fronts. J Geophys Res 107:8040. doi: 10.1029/2000JD000263

Rossow WB, Schiffer RA (1999) Advances in understanding clouds from ISCCP. Bull Am Meteor Soc 80:2261-2288

Rossow WB, Walker AW, Beuschel DE, Roiter MD (1996) International Satellite Cloud Climatology Project (ISCCP), Documentation of New Cloud Datasets

Saji NH, Yamagata T (2003) Possible impacts of Indian Ocean Dipole mode events on global climate. Clim Res 25:151-169

Saji NH, Goswami BN, Vinayachandran PN, Yamagata T (1999) A dipole mode in the tropical Indian Ocean. Nature 401:360-363

Sen PK (1968) Estimates of the regression coefficient based on Kendall's Tau. Am Stat Assoc J 63:1379-1389

Shuttleworth WJ (1989) Micrometeorology of temperate and tropical forest. Phil Trans Roy Soc (Lond) B 324:299-334

Wang C (2002) Atlantic climate variability and its associated atmospheric circulation cells. J Clim 15:1516-1536

Wang H, Fu R (2002) Cross-equatorial flow and seasonal cycle of precipitation over South America. J Clim 15:1591-1608

Warren SG, Eastman RM, Hahn CJ (2007) A survey of changes in cloud cover and cloud types over land from surface observations, 1971-96. J Clim 20:717-738

Wielicki BA, Wong T, Allan RP, Slingo A, Kiehl JT, Soden BJ, Gordon CT, Miller AJ, Yang S, Randall DA, Robertson F, Susskind J, Jacobowitz H (2002) Evidence for large decadal variability in the tropical mean radiative energy budget. Science 295(5556):841-844

Wright SJ, van Schaik C (1994) Light and the phenology of tropical trees. Am Nat 143:192-199

Yoon JH, Zeng N (2010) An Atlantic influence on Amazon rainfall. Clim Dyn 34:249-264

Zhang Y, Rossow WB, Lacis AA (1995) Calculation of surface and top of atmosphere radiative fluxes from physical quantities based on ISCCP datasets, 1. Method and sensitivity to input data uncertainties. J Geophys Res 100:1149-1165

Zhang Y, Rossow WB, Lacis AA, Oinas V, Mishchenko MI (2004) Calculation of radiative fluxes from the surface to top of atmosphere based on ISCCP and other global data sets: refinements of the radiative transfer model and the input data. J Geophys Res 109:D19105. doi:10.1029/2003JD004457 